\title{
The Analysis of the SPA Apparel Company Strategy
}

\author{
Huijuan Du ${ }^{\mathrm{a}}$, Yanjun Huang ${ }^{\mathrm{b}}$, Yan Liu ${ }^{*}, \mathrm{c}$ \\ College of Quartermaster Technology, Jilin University, Changchun, 130062, China \\ ad896065365@qq.com, bhuangyanj@jlu.edu.cn, c1403686446@qq.com
}

\begin{abstract}
SPA is internationally recognized as a successful business model, the model successfully helped GAP, UNIQLO, ZARA, H\&M and other clothing own brands, as these enterprises entered Chinese market, and developed a good market, SPA mode has also been a concern. There are also many companies exploring the application of SPA mode, such as HEILAN HOME, N\&Q have made a good score, but it has not formed a complete system. This paper puts forward strategic proposals of SPA mode by analyzing the various enterprises
\end{abstract}

\section{Keywords-SPA mode, clothing brand, strategy, Chinese}

\section{The Definition Of Apparel SPA Mode}

SPA (Specialty Store Retailer of Private Label Apparel) was first used by the famous American clothing retail giant GAP apparel company. Studies have shown that SPA take an integrated way from product planning, design, production to retail sales by the Corporation, so that products can better meet consumer demand, reduce costs, and in a very short period of time to respond to consumer demand quickly. The mode was a creative concept proposed by the US GAP's former chairman Donald Fisher in the 1986 annual report on the accounts for a new business system of the company was about to start. SPA was the first that made public at this time, and become another original word of the fashion industry. This is the first generation of SPA, UNIQLO as the representative of the second generation of SPA has a successfully application and promotion. And the third generation of SPA is ZARA and H\&M [1].

SPA mode has the following features: 1 . Direct control of consumer information; 2. Simplify the supply chain, to substantially reduce logistics costs and time; 3 . Minimize the risk of demand forecasting to supply rapidly; 4 . Unique, innovative product planning; 5. Achieve quick return of funds [2].

\section{THE ANALYSIS OF THE INTERNATIONAL SPA COMPANIES' DEVELOPMENT}

SPA in some countries is a very mature fashion brand retail mode. GAP, UNIQLO, H\&M, ZARA, etc., these brands in the Chinese market all have wonderful sales. They are obtained brand development and growth through the SPA mode. Therefore, Good retail mode is a powerful tool to enhance the international competitiveness of Apparel Company.

\section{A. The SPA mode of GAP}

GAP regards "Made - Retail" integration as the core, pursuits the traditional assembly line production of "less style, high-volume, continuous goods". It bases on middle and low casual style instead of emphasizing fashion brand. This mode has become a fundamental system of GAP's business development since the 60s. The period of GAP's SPA mode was more emphasis on branding and terminal operators, to outsource production. GAP have more than $98 \%$ of the product are produced outside the United States.

From the 1990s, GAP began the rapid expansion of the market. Stores increased rapidly from 1092 to 2848 during 1990 to 2000 . And store size was also from $400 \mathrm{~m}^{2}$ up to $1000 \mathrm{~m}^{2}$. GAP's sales area in this period had increased 5.6 times. And its revenue topped to $\$ 10$ billion, net profit more than 1 billion US dollars in 1999. From the lowest point in 1983 to the highest point in 2000, GAP's shares rose more than 300 times, creating a myth of the capital market.

\section{B. The SPA mode of UNIQLO}

UNIQLO is very similar to GAP; they are both pursuing a full range of shopping patterns. UNIQLO is a typical brand that uses the SPA mode. UNIQLO's business mode mainly include: 1 . Reflect the breadth of product; 2 . Standardization of shop, rely on management guidelines make store layout, merchandise, the price is the same; 3 . Reduce the number of styles, to enhance a single style sales quantity to reduce the cost of goods, for the price advantage; 4 . Warehouse sales, reduce storage costs, labor costs.

Many Japanese retailers are due to the impact of the global financial crisis into a slump, the performance is deteriorating, but "UNIQLO" exists with a dominant win attitude. When GAP was developing rapidly, the sales of UNIQLO was only just over 100 billion yen. However, in 2013, the sales of UNIQLO had exceeded 1 trillion yen (Table 1). The number of stores also reached 2449 in 2013(Table 2). It is enough to see the advantages of UNIQLO SPA. 
TABLE 1 UNIQLO'S TOTAL SALES FROM 2011 TO 2013

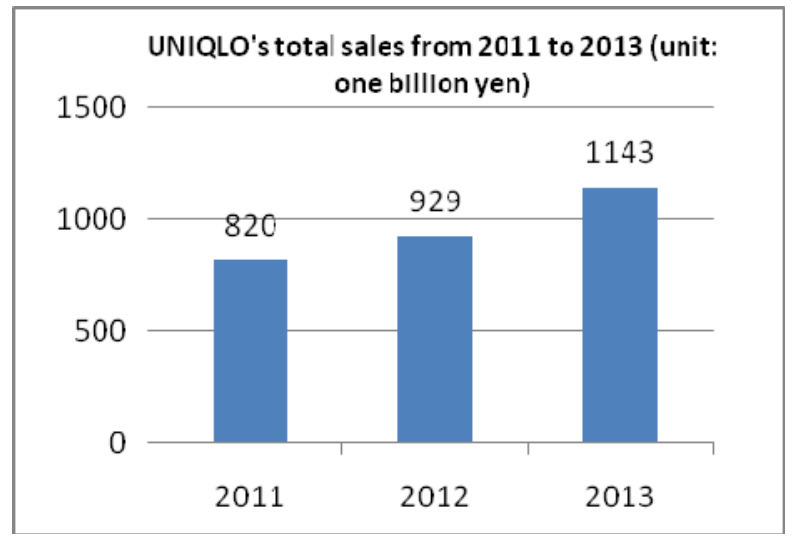

TABLE 2 THE NUMBER OF UNIQLO'S STORES FROM 2011 TO 2014

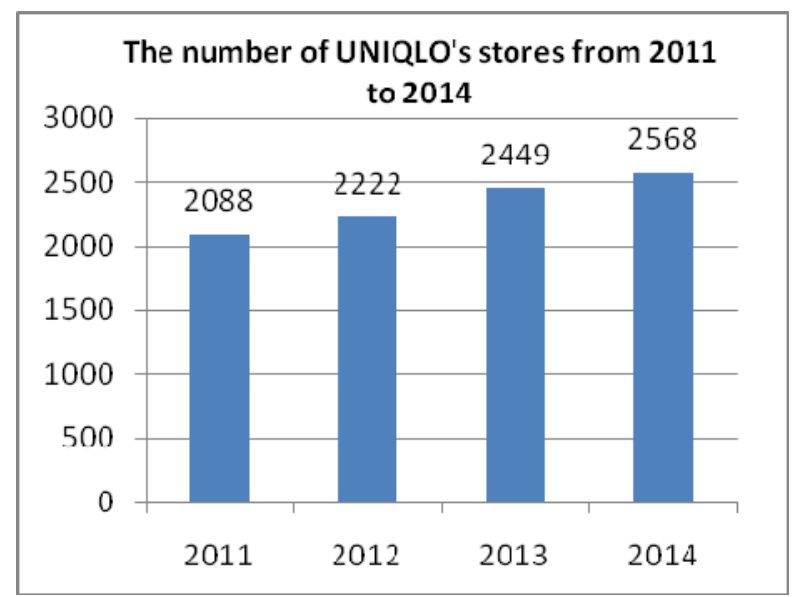

\section{The SPA mode of ZARA}

Zara was founded in 1975; the SPA mode of Zara is fashion, fast, low-cost. It is such a fast, imitation fashion competitive mode to win the market, is a model of SPA business mode. In the past 10 years, ZARA developed rapidly keeping turnover to $20 \%-30 \%$.

ZARA companies adhere to the principle of own and operate a network of almost all stores. While investing heavily in building their own factories (currently there are 22 self-owned factories). So it will be able to grasp the needs of customers accurately, control the production, and respond to market demands quickly. In addition, it adheres to product management of "fast, small, several types". Guarantee to remain in sync with fashion, at the same time, develop new models, and rapid introduce of new products. And each style introduced in each store is only a few number, this man-made causes "out" is in order to achieve the goal of store merchandise is updated twice a week [3].

ZARA has a rapid response supply chain, including the organization and product design, procurement and production, product distribution and sales and feedback four main areas. ZARA increase the velocity of circulation of the product to the extreme through the entire supply chain, and with the construction of vertical integration. According to 2009 MillwardBrown brand value ranking, ZARA stand the third place of clothing brand ranking (Table 3). ZARA put a lot of hundred luxury brands left behind by using SPA for only a few years (Table 4).

TABLE 32009 MiLLWARDBROWN CLOTHING BRAND VALUE RANKING

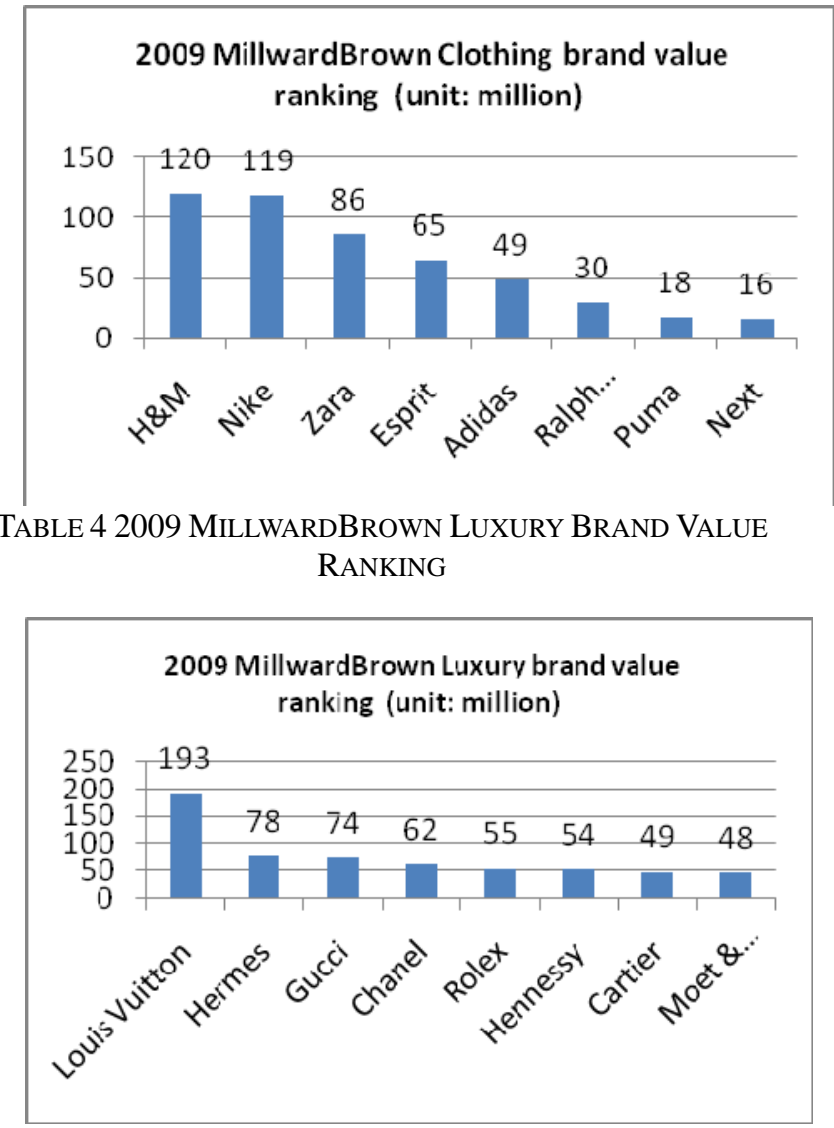

\section{THE ANALYSIS OF CHINESE SPA COMPANIES' DEVELOPMENT}

Turn to see the Chinese situation, there are some companies clearly state SPA application, put forward the company's business strategy; there are some companies did not submit the application of SPA, but companies in the course of business strategies are similar with SPA. From all indications, we can easily see that, although there is no Chinese enterprises SPA application in the full sense, but many companies are equipped SPA features with SPA applications trend.

\section{A. The SPA mode of N\&Q}

Fujian N\&Q Limited regarding SPA as the main mode listed on the HKEx board in January 9, 2014, is the first "fast fashion" brand of men in Hong Kong stock market. 
N\&Q's successful listing made the entire clothing sector pay attention to the SPA mode again.

$N \& Q$ is the fashion leader in the retail business. It first put forward the fashion retail marketing concept PFM (Parity, Fashion, and Multiple). It clear the corporate mission of "to provide customers with value for money fashion", relying on differentiated market positioning strategy, efficient supply chain management, and innovative marketing strategies in Chinese market gained some success. N\&Q's SPA first makes brand positioning follow the trend, and then is the sustained production of "super multi-style, a small group of small amount". By SPA, N\&Q can not only take advantages of the flat channel mode parity mode, it can also control the retail terminal in time to meet consumer demand for control purposes ${ }^{[3]}$.

N\&Q had achieved revenues of 162 million in 2008. 2010-2013, its revenue was 322.2 million, 467.8 million, 572.1 million and 682 million (Table 5), the average annual growth rate is about $33.3 \%$. Terms of stores, in 2008 N\&Q’s stores is 107, 2010 was 225, in 2011 to 366 and in 2012 to 420(Table 6). By October 31, 2013, N\&Q has a total of 438 retail outlets in the country, 225 retail outlets for direct-sale stores, 213 retail outlets for the franchisee.

TABLE 5 N\&Q’s TotAl SALES From 2010 TO 2013

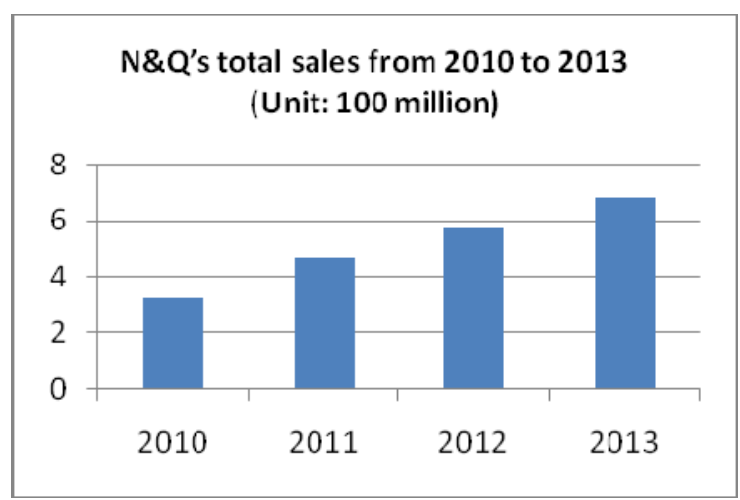

TABLE 6 N\&Q’s NuMBER OF STORES From 2010 TO 2013

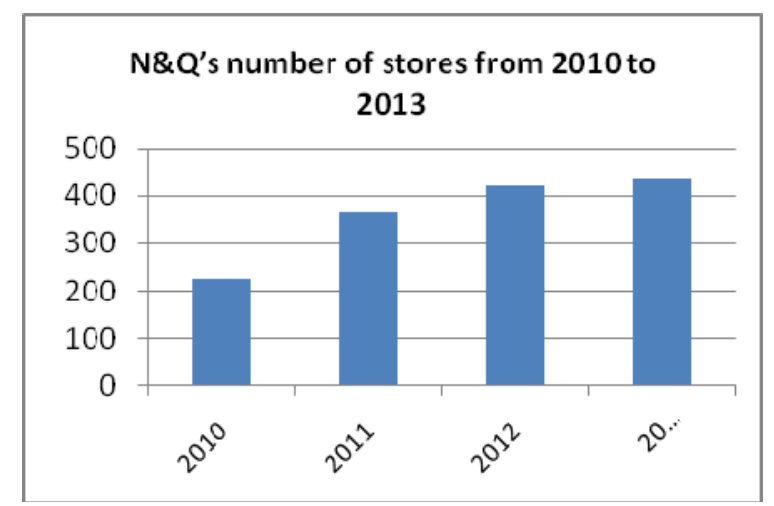

\section{B. The SPA mode of HEILAN HOME}

Although in the background of clothing consumption overall downturn, HEILAN HOME also rushed in the front of the market. In the past Two-Eleven Consumer Boom, HEILAN HOME achieved 91.98 million in sales.

HEILAN HOME uses the name of Canal Scientific And Technological Co., Ltd. to listed this year, and become the largest clothing companies in A-shares. August released mid-year report, the first half attributable to shareholders of listed companies net profit of 1.228 billion, an increase of $82.79 \%$, operating income of 5.683 billion, an increase of $61.53 \%$. In contrast, in the case of Chinese apparel industry stocks run up, HEILAN HOME's achievements thanks to the company's innovative business mode. HEILAN HOME has a precise positioning, which is very similar to UNIQLO. It pursues high-quality and popular price. However, in the style it purses changing, at the headquarters of the design and development room, there are hundreds of designers. HEILAN HOME business model is different from other brands, mainly include: 1 . A joint mode with suppliers makes the quality of goods and suppliers tied together closely to reach win-win. Unmarketable product inventory borne by the supplier, and it make the enterprise itself inventory, reduce operating costs. 2. For shops, HEILAN HOME fully grasps franchise, the franchisee bear only a few stores rent, utility costs, employee bride price and ownership of the store. This enables the unified management of the store, so that the image can be more unified, and the deployment of the goods will be more flexible. 3. HEILAN HOME adopts flat logistics mode, it has invested 1.6 billion to build their own logistics industrial park for the headquarters of shipping methods, in order to improve logistics efficiency, reduce logistics costs, and lay a solid foundation for the implementation of price strategy ${ }^{[3]}$.

Over the past five years, the number of chain stores develops from 655 to 3164, only the first half of this year, it added 277. With the expansion of the store is bright business data, from 2009 to 2013, Sea Orchid House revenue and net profit growth were as high as $50.8 \%$ and $45.6 \%$.

\section{The Suggestions Of ChINESE SPA ENTERPRISES' STRATEGIC}

SPA is a powerful tool towards the weak, not only for large companies, but also for small garment enterprises is good news. As for the Chinese market, although many companies have begun to implement the SPA mode in business operations applications, however, the development is still not mature enough; it cannot achieve the level of development different from the international markets. Through the analysis of Chinese and international enterprises SPA, concluded the following, for Chinese clothing brand to enhance brand value as the reference. 


\section{A. Improve the brand with suppliers, manufacturers of cooperation strategy}

At present, many Chinese brands are in a fragmented state, enterprises, suppliers, and manufacturers regard their own interests as large, and not form a chain of interest. When the suppliers, manufacturers and enterprises have the same target, it can increase production speed, improve product quality and reduce the cost of goods, and the brands' competitiveness will finally upgrade.

\section{B. Strengthen the brand marketing}

Due to the limitations of Chinese brand development course, many brands are carried out by the regional agency in charge of sales. Agents and franchisees for a independent brands, is critical way to generate interest. However, brand managers will lose the right to shop for unified management and cannot guarantee the unity of the terminal store image. If store image becomes diversiform, the product orientation will be an impact. Not only like that, brand managers also unable to transfer goods quickly and accurately, in order to achieve the purpose of rapid digestion products. Therefore, strengthen marketing efforts for the development of an independent brand has important influence.

\section{Information Sharing}

Apparel products are market - driven to meet consumer demand as the goal, therefore, market information, consumer demand for information is the core of apparel products. Information sharing mechanism requires that all terminals must send the store daily sales and customer demand information back to headquarters via the information system on time. Then companies can accord to product sales, market reaction to good advance chasing a single, a good product on the part of the regional timely allocation. So it can maximize common interests.

Information sharing system enables the company to obtain the original sales data, detailed to each product sold a few single, size, color, quantity, selling time, payment, discount information, price adjustment. The company can base on these data do analysis, understand the market demand, the market judge. Combined with the analysis results, trends can be a new season of merchandise planning.

\section{Enhance merchandising capabilities}

SPA advocated a weekly basis trimming type merchandising mode. The first step is to decrease the time from placing an order to supply commodities cycle, build establishment of production systems to additional orders, in order to reduce inventory and losses; the second step is the timing of the collection of major shops' sales information, after analysis, to achieve a weekly basis of product planning.

Merchandising can be said that is the core of the SPA, merchandising determines the structure of the terminal display of goods, color distribution, display effects and so on. Merchandising determines the design direction. Merchandising division will be based on standard store for goods planning and categories planning, and designers will design according to the planning, then production and sales. However, many Chinese enterprises are lack of professional planner, just make a simple product merchandising categories according to the reaction of the market.

\section{CONCLUSION}

During the last 20 years of the development between SPA mode, it has made "GAP", "UNIQLO", "ZARA" and other such international brands, it can be seen, SPA mode is a worthy mode of operation. Through the applications of "HEILAN HOME ", "N\&Q" and other brands , SPA has made many Chinese brands' attention. SPA mode development process has a long way to go, due to limitations of the market environment, the different situation of each enterprise itself, enterprises in the development of the SPA mode, should combine with their own brand, to make appropriate modifications. Not every way can be efficient. I hope companies can be able to learn from successful cases, with its own conditions to innovate and create a SPA mode has its own characteristics.

\section{CORRESPONDING AUTHOR}

Name: Yan Liu, Email: 1403686446@qq.com, Mobile phone: 13756073064

\section{REFERENCES}

[1] L.N.Tong, Revelation of Fujian N\&Q's SPA mode, China Fashion Weekly. 2014-2-21 (005).

[2] UTA fashion media center, Do you use SPA? Franchise Market Magazine. 09 (2008) 74-75.

[3] Q.Y.Zhao, Applied research on SPA in Chinese apparel enterprises, Beijing Institute of Clothing Technology, Beijing, 2010, 32-35.

[4] Q.B.Xu,L.Q.Zou,M.Li, From traditional to modern - HEILAN HOME's transformation development survey, The Masses.10 (2014) 47-48. 